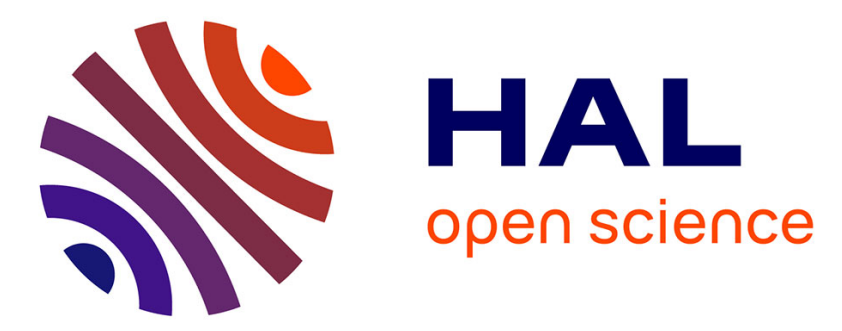

\title{
Damage modelling in nodular cast iron
}

\author{
M. Dong, G. Hu, A. Diboine, D. Moulin, C. Prioul
}

\section{To cite this version:}

M. Dong, G. Hu, A. Diboine, D. Moulin, C. Prioul. Damage modelling in nodular cast iron. Journal de Physique IV Proceedings, 1993, 03 (C7), pp.C7-643-C7-648. 10.1051/jp4:19937103 . jpa-00251720

\section{HAL Id: jpa-00251720 https://hal.science/jpa-00251720}

Submitted on 1 Jan 1993

HAL is a multi-disciplinary open access archive for the deposit and dissemination of scientific research documents, whether they are published or not. The documents may come from teaching and research institutions in France or abroad, or from public or private research centers.
L'archive ouverte pluridisciplinaire HAL, est destinée au dépôt et à la diffusion de documents scientifiques de niveau recherche, publiés ou non, émanant des établissements d'enseignement et de recherche français ou étrangers, des laboratoires publics ou privés. 


\title{
Damage modelling in nodular cast iron
}

\author{
M.J. DONG, G.K. HU, A. DIBOINE*, D. MOULIN** and C. PRIOUL \\ Laboratoire MSS/MAT, URA 850 du CNRS, Ecole Centrale Paris, 92295 Châtenay Malabry, France \\ * Renault Automobiles, Billancourt, France \\ ${ }^{* *} C E A, D M T, C E N$ Saclay, France
}

\begin{abstract}
The damage mechanism of two types of ductile cast iron have been studied by precise microscopical observations and careful chemical, morphological and mechanical characterizations. Two modes of damage are observed as a function of graphite morphology: the void growth at the pole of the graphite or the void growth by internal cracking. These two types of damage are considered by micro mechanical method. The plastic deformation of the matrix is taken into account and the damage processes are modeled: replacing the nodule by a void or anisotropic inclusion for void growth at interface case, introducing two population of inclusions (nodule and penny-shape crack) for internal cracking case. These results show that graphite nodules in cast iron serve essentially as void nucleation sites and that as soon as debonding occurs, the nodules can be replaced by voids (cast iron A). The predicted local of flow stress in the case of internal cracking is higher than in the case of the voids one. This seems to be confirmed by the experimental result of cast iron B (contents more internal cracks than cast iron A). A comparison between analytical and numerical results is presented.
\end{abstract}

\section{INTRODUCTION}

Low cost and reliability make the casting process well adapted to mass production. For these reasons nodular cast iron is a good candidate to realize components for automotive industry and nuclear applications. Nevertheless failure safe design of critically stressed components requires a thorough knowledge of the mechanical properties and defect tolerance of the material. Especially ductile fracture, which is the limiting process in the plastic deformation of ductile cast iron, has been extensively studied [15]. So, the influence of distribution and size of nodules [6], stress triaxiality [7,8], as well as thermal treatment [9] were characterized.

Recently, some of the authors have proposed a tentative numerical modeling of the stress-strain behavior of ductile cast iron [10]. Damage observations in cast iron A and B show that the local plastic deformation of the matrix is followed by nodule matrix interface decohesion in the early stage of macroscopic yielding. This modeling considers that nodules can be replaced by voids, as soon as interface decohesion occurs. Reasonable agreement was obtained between numerical modeling and experimental results.

The purpose of the present study is first to extend damage observations to different cast irons in order to study the damage mechanisms for the two different nodular cast irons. Consequently, precise damage observations have been correlated to careful chemical, morphological and mechanical characterization of two different materials. The second objective is focused on the understanding of the mechanisms responsible for the non-linear behavior of the cast iron, and to establish the relationship between microscopic damage observation and macroscopic mechanical behavior.

\section{Material characterization}

\section{1 chemical analysis}

Two cast irons were studied. The first one, cast iron A, is a purely ferritic nodular cast iron, whereas the other is ferrito-perlitic cast iron containing $5 \%$ perlite (cast iron B). These materials were characterized chemically, morphologically and mechanically.

The chemical composition of the tested materials is presented in table 1 for the global analysis.

Table 1: Global chemical analysis (weight \%) of the different cast iron

\begin{tabular}{|c|c|c|c|c|c|c|c|c|c|c|}
\hline & $\mathrm{C}$ & $\mathrm{Si}$ & $\mathrm{Mn}$ & $\mathrm{S}$ & $\mathrm{P}$ & $\mathrm{Mg}$ & $\mathrm{Cu}$ & $\mathrm{Ni}$ & $\mathrm{Cr}$ & $\mathrm{Fe}$ \\
\hline cast iron $\mathrm{A}$ & 3,35 & 2,25 & 0,30 & 0,006 & 0,025 & 0,039 & 0,06 & 0,04 & 0,02 & bal \\
\hline cast iron B & 3,65 & 2,75 & 0,24 & 0,012 & 0,03 & 0,048 & 0,09 & 0,56 & $<0,01$ & bal \\
\hline
\end{tabular}


Table 1 shows that cast iron A and B differ mainly by their Silicon and Nickel content. Nevertheless, this global analysis gives only qualitative indications concerning the matrix composition. Since the mechanical behavior of the matrix is very sensitive to Silicon and Manganese content, this chemical analysis has been completed by local X Ray microprobe analysis of the matrix. Silicon and Manganese were shown to be homogeneously distributed in the matrix. The chemical composition of the different ferritic matrix, as determined by X Ray microprobe, is reported in Table 2. The Vickers micro hardness of these two materials is also presented.

Table $2: \mathrm{Si}$ and $\mathrm{Mn}$ content and micro hardness of the matrix

\begin{tabular}{|c|c|c|c|}
\hline & $\mathrm{Si}$ & $\mathrm{Mn}$ & $\mathrm{Hv}$ (matrix) \\
\hline cast iron A & $2,6 \%$ & $0,2 \%$ & 170 \\
\hline cast iron B & $3,3 \%$ & $0,15 \%$ & 203 \\
\hline
\end{tabular}

\subsection{Morphological analysis}

A quantitative analysis of the two materials have been performed on a Cambridge (LQ 500) Image Analyzer, in line with a video camera mounted on an optical microscope. Statistical validity of the results is obtained using the digitally driven motorized stage of the microscope which allows for a large number of automatically scanned areas. Two characteristics are measured: graphite volume fraction and nodule shape factor. Introducing the shape factor $F$, as $F=p^{2} / 4 \pi A$ ( $p$ and $A$ being respectively the perimeter and area of each nodule), the nodules can be separated in three different classes which evaluate various degree of nodule sphericity. For $1 \leq \mathrm{F}<1,2$ nodules which are labeled as "type $A$ " are nearly perfectly spherical, whereas degenerated graphite correspond to "type C" nodules, with 1,54 $\leq$ F. Intermediate class B nodules, for $1,2 \leq F<1,54$ exhibit an ondulating interface. Table 3 which summarizes the results shows that the graphite volume fraction is quite similar for the two materials. The main difference appears in the shape factors since cast iron A cast iron contains predominantly well developed A or B type nodules whereas degenerated graphite is present in the cast iron B.

Table 3 : Quantitative analysis of graphite nodules

\begin{tabular}{|c|c|c|c|c|}
\hline graphite & Total (\%) & Type A & Type B & Type C \\
\hline cast iron $\mathrm{A}$ & $\overline{7,43}$ & $1,50 \quad(20,2 \%)$ & $5,37 \quad(72,3 \%)$ & $0,56 \quad(7,5 \%)$ \\
\hline cast iron B & 8,56 & $0,30 \quad(3,5 \%)$ & $4,45 \quad(52,0 \%)$ & $3,81 \quad(44,5 \%)$ \\
\hline
\end{tabular}

\subsection{Mechanical properties}

Tensile tests on an Instron screw driven machine were performed on cylindrical specimens (diameter $5 \mathrm{~mm}$, gauge length $25 \mathrm{~mm}$ ) with a $610^{-4}$ strain rate. We have reported in Figure 1 the stress strain curve of the two materials and Table 4 summarizes the main results which will be analyzed further on in the light of damage observations.

\begin{tabular}{|} 
Table 4: Mechanical properties (tensile test $\dot{\varepsilon}=610^{-4} \mathrm{~s}^{-1}$ ) \\
\begin{tabular}{|c|c|c|c|c|}
\hline & $\mathrm{E}(\mathrm{GPa})$ & $\sigma_{\mathrm{y}}(\mathrm{MPa})$ & $\sigma_{\mathrm{UTS}}(\mathrm{MPa})$ & $\mathrm{A} \%$ \\
\hline cast iron A & 187 & 260 & 393 & 23 \\
\hline cast iron B & 184 & 329 & 477 & 19 \\
\hline
\end{tabular}
\end{tabular}

\subsection{Damage observations}

Comparison between Figures 2 and 3 shows that damage mechanisms are strongly dependent on graphite morphology. In agreement with previous experimental results and modeling [10], Figure 2 confirms that Type A nodules lead to an early decohesion of the graphite matrix interface initiating at the pole cap of the nodules, perpendicularly to the macroscopic tensile stress direction. In contrast, damage of $\mathrm{C}$ type nodules occurs predominantly in the form of internal cracking along the equatorial plane of the graphite nodule (Fig. 3). The crack tip is impeded in the ductile matrix thus triggering shear bands in the maximum shear direction. 


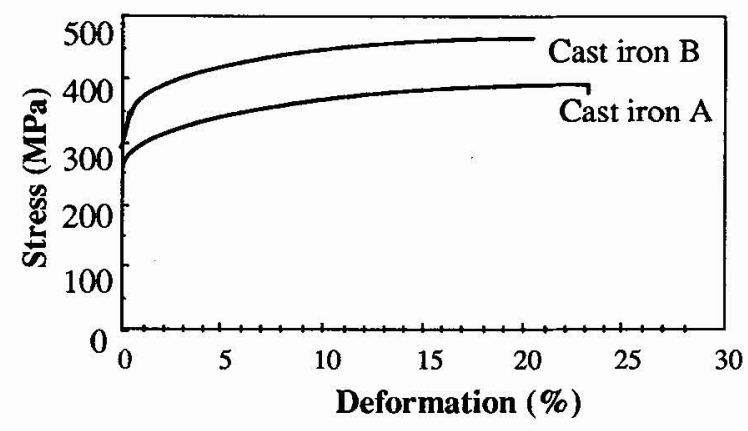

FIG. 1. Tensile stress strain curves in various cast irons

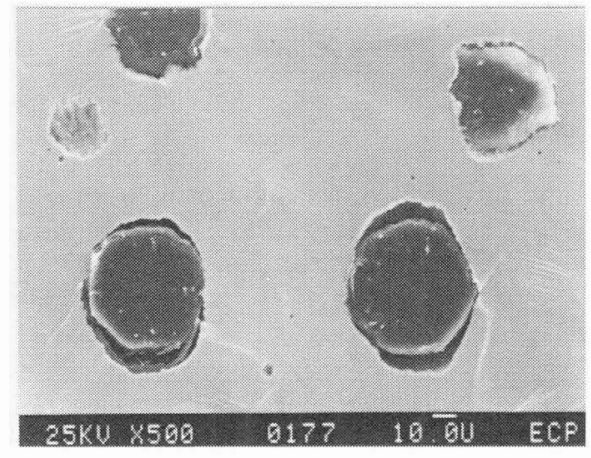

FIG. 2. Growth of the void at interface

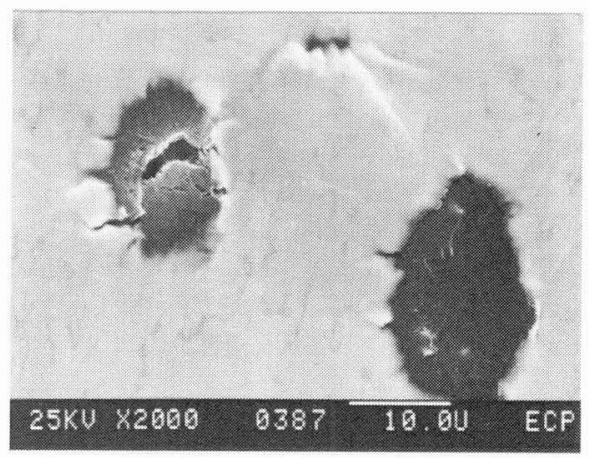

FIG. 3. Growth of the void at internal crack

\section{MODELING}

In this section, two previous forms of damage are analyzed by micro mechanics method. The void growth from nodule and matrix interface is considered by replacing the nodules by voids and anisotropic inclusions (with zero module in the tensile direction). The internal cracking is considered by inducing two populations of inclusions (nodules and penny-shape cracks).

Mechanical behavior of each constituent must be known to build up a predicting model for the mixture properties. The physical bases of the constitutive laws of both graphite nodules and ferritic matrix have been established in a previous work [10].

The Young's modulus for graphite nodules is taken as $\mathrm{E}_{\mathrm{g}}=27 \mathrm{GPa}$ and $v_{\mathrm{g}}=0.22$. From the microscopic observations, we found that graphite deforms in a purely elastic manner [10].

The Young's modulus for cast iron $\mathrm{A}$ is $\mathrm{Ec}=187 \mathrm{GPa}$, as measured by tensile test, whereas usual values are taken for the iron matrix : $\mathrm{E}_{\mathrm{m}}=210 \mathrm{GPa}$ and $\mathrm{v}_{\mathrm{m}}=0.3$.

The global non-linear behavior of cast iron is studied from a microscopic point of view (using iron matrix and graphite nodule mechanical properties) with the micro mechanic method developed by Weng[11] and Bourgeois[12]. These analyses are based on Eshelby equivalent inclusion method [13] lately extended for finite inclusion concentration by Mori-Tanaka[14]. The decreasing constraint power of the matrix during plastic deformation is taken into account using the matrix secant modulus.

The nodular cast iron is considered to be a continuous matrix reinforced with isotropic graphite nodules. The reinforcements are assumed to be spherical.

A representative volume is considered and surface traction is prescribed on its boundary. It gives rise to an average stress $\sum$ in the composite material. To facilitate the analysis an identical shaped comparison material having the matrix properties is also considered under the same surface traction. The average strain produced in the nodular cast iron and comparison material are given by: 


$$
\begin{aligned}
& \Sigma=\mathrm{LE} \\
& \Sigma=\mathrm{L}^{0} \mathrm{E}^{0}
\end{aligned}
$$

$\mathrm{L}$ and $\mathrm{L}^{0}$ are respectively the composite and the matrix tensor. $\mathrm{L}$ is to be determined. The matrix is denoted as the phase 0 , and the graphite nodules as phase 1 .

Taking the comparison material as matrix, $\mathrm{E}^{0}$ is the strain that would result in the matrix if there were no reinforcement.

Under the prescribed stress $\sum$, the average stress in the matrix is defined by:

$$
\widetilde{\sigma}^{0}=\Sigma+\widetilde{\sigma}=\mathrm{L}^{0}\left(\mathrm{E}^{0}+\tilde{\varepsilon}\right)
$$

$\widetilde{\varepsilon}$ and $\widetilde{\sigma}$ are respectively the average perturbed strain and stress due to the presence of the graphite nodules. By means of the Eshelby's equivalent inclusion method, the stress in the graphite nodules is expressed as:

$$
\begin{aligned}
\sigma^{1}= & \Sigma+\widetilde{\sigma}+\sigma^{1 p t}=L^{1}\left(E^{0}+\widetilde{\varepsilon}+\varepsilon^{1 p t}\right) \\
& =L^{0}\left(E^{0}+\widetilde{\varepsilon}+\varepsilon^{1 p t}-\varepsilon^{1^{*}}\right)
\end{aligned}
$$

$\varepsilon^{1 \mathrm{pt}}$ : is a perturbed strain with respect to the average strain in the matrix.

$\varepsilon^{1 *}:$ is eigen-strain introduced by Eshelby [14].

and $\quad \varepsilon^{1 \mathrm{pt}}=\mathrm{S}^{1} \varepsilon^{1^{*}}$

$S^{1}$ : is the Eshelby's tensor, for an isotropic matrix, it can be found in Ref [15], for a uniform strain and stress field within spherical inclusion. $S^{1}$ is a function of the matrix Poisson's ratio and of the graphite aspect ratio.

So, $\quad \varepsilon^{1^{*}}=\mathrm{Q}^{1}\left(\mathrm{E}^{0}+\tilde{\varepsilon}\right)$

with $\quad Q^{1}=-\left[\left(L^{1}-L^{0}\right) S^{1}+L^{0}\right]^{-1}\left(L^{1}-L^{0}\right)$

The stress in the graphite nodule and in the matrix must be balanced with the external stress $\Sigma$ :

$$
\begin{aligned}
\Sigma & =c_{0} \bar{\sigma}^{0}+c_{1} \sigma^{1} \\
& =c_{0} L^{0}\left(E^{0}+\widetilde{\varepsilon}\right)+c_{1} L^{0}\left(E^{0}+\widetilde{\varepsilon}+\varepsilon^{1 p t}-\varepsilon^{1 *}\right)
\end{aligned}
$$

$c_{1}:$ is the volume fraction of the graphite.

$$
\widetilde{\varepsilon}=-c_{1}\left(\varepsilon^{1 p t}-\varepsilon^{1^{*}}\right)=-c_{1}\left(S^{1}-I\right) \varepsilon^{1^{*}}
$$

$\mathrm{I}:$ is the identity tensor.

$$
\tilde{\varepsilon}=-\left[I+c_{1}\left(S^{1}-I\right) Q^{1}\right]^{-1}\left[-c_{1}\left(S^{1}-I\right) Q^{1}\right] E^{0}
$$

The global strain of cast iron is given by averaging those of graphite and of the matrix:

$$
\begin{aligned}
& E=c_{0}\left(E^{0}+\widetilde{\varepsilon}\right)+c_{1}\left(E^{0}+\widetilde{\varepsilon}+\varepsilon^{1 p t}\right)=E^{0}+c_{1} \varepsilon^{1 *} \\
& L=L\left\{1 I+\left(c_{1} Q^{1}\right)\left(I+c_{1}\left(S^{1}-I\right) Q^{1}\right)^{-1}\right\}-1
\end{aligned}
$$

Weng [13] demonstrated that the effective modulus tensors resulting from the Mori-Tanaka approach under prescribed traction or displacement are identical.

The average strain in the matrix is:

$$
\varepsilon=\mathrm{E}^{0}+\tilde{\varepsilon}
$$

It can be expressed as a function of the prescribed stress. When the matrix undergoes a uniform plastic deformation $\varepsilon^{\mathrm{P}}, \mathrm{L}^{\circ}$ must be the secant modulus of the matrix which depends on the plastic deformation of the matrix $\varepsilon^{P}$. Imposing the condition that the average stress and strain in the matrix satisfy the matrix constitutive relation, $\left(\mathrm{J}_{2}\right.$ - flow rule, and incompressibility), for a prescribed $\Sigma$, we know $\varepsilon^{\mathrm{P}}$ then $\mathrm{L}^{\mathrm{O}}$ and $\mathrm{E}$, so the relation between $\Sigma$ and $\mathrm{E}$ can be determined.

The two types of the damage (figure 4) are modeled by this method.

--- The damage mode of void growth at interface can be modeled by considering $L 1=0$, that is replacing graphite by voids (figure 5. a) or by considering graphite as an anisotropic inclusion with the zero modulus in the tensile direction and $27 \mathrm{GPa}$ in the other directions (figure 5. b).

--- The damage mode of internal cracking is modeled by considering two populations of inclusions (nodule and penny-shape crack) (figure 5. c), the aspect ratio $1 \%$ is taken as penny-shape crack. 
--- The perfect interface (figure 5. d) gives a predicted undamaged material behavior.

The predicted stress strain curve of these models are shown in figure 6. It shows that, considering nodule as voids (model a) the modeling gives a reasonable result as compared with the experimental one obtained for cast iron A. The model of the anisotropic reinforcement (model b) is used to take into account the lateral constraint on nodules and this model gives results (not represented) very close to the result obtained by replacing the graphite by voids. The model of internal cracking (model c) results in a predicted local of flow stress higher than the two others (model a, b). This seems to be confirmed by cast iron B behavior in which are more degenerated graphites, so more internal cracking is observed than in cast iron A. All these results are more reasonable than that of the perfect interfaces model (model d).
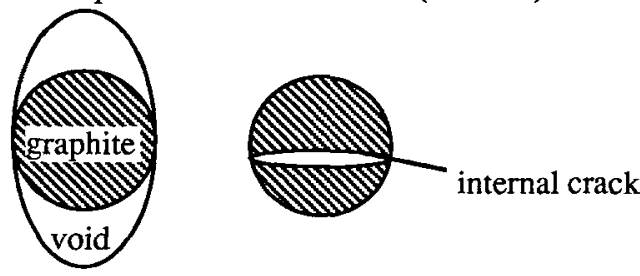

FIG. 4. Scheme of the two damage processes

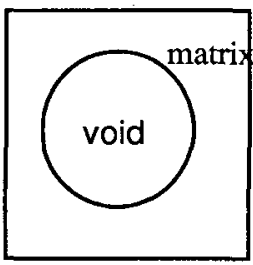

(a)

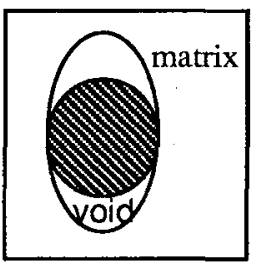

(b)

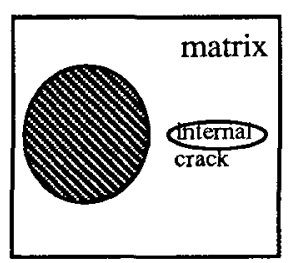

(c)

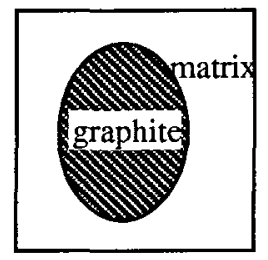

(d)

FIG.5. Models used in analytical method

(a). the graphite is replaced by void;(b). anisotropic reinforcement with zero module in sense traction; (c). internal cracking mode by putting a crack in the matrix; (d). the perfect interface

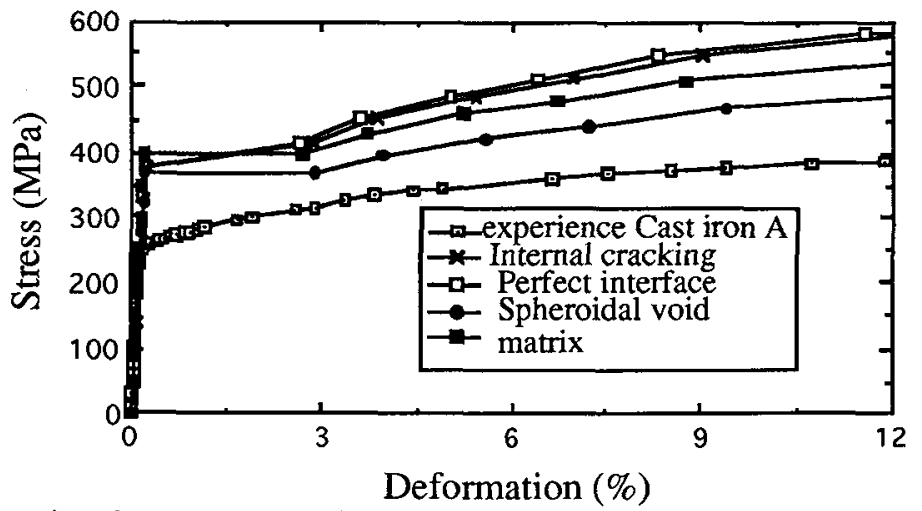

FIG. 6. Comparison between the predicted behavior and the experimental result in cast iron $A$

\section{Discussion}

The yield strength, the ultimate tensile strength and the micro hardness of the cast iron $B$ are higher than these of cast iron A. These differences between the two materials can be explained by two contributions. The first one is due to the different damage mechanisms as shown by the modeling. The second one is the result of the difference between Silicon content of the matrix which is well known to strongly influence the mechanical behavior of cast iron. The lower ductility of cast iron B can tentatively be explained by the detrimental effect of internal cracking on ductility. 
For this analytical method, where the inclusion is considered to be a void, the void growth mechanism is not taken into account. Numerical methods taking into account this void growth mechanism can indeed give a better approximation (figure 7).

As the Mori-Tanaka method is a mean field one, it doesn't include the local effect, so the effect of the local plastic deformation induced by the internal cracking can not be taken into account and numerical methods could be more adequate to model this damage mechanism.

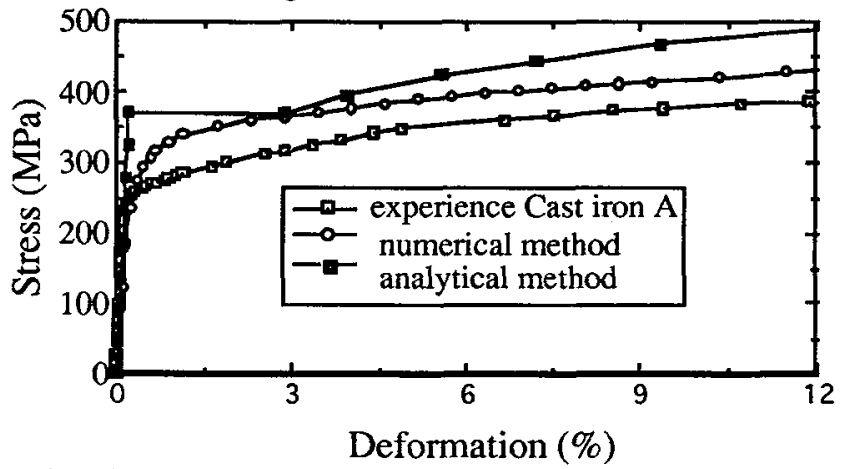

FIG.7. Comparison between the predicted behavior by analytical and numerical method

\section{Conclusions:}

The yield strength and ultimate tensile strength of cast iron are governed both by the chemical composition of the matrix and by the shape of the graphite nodule.

The different shapes of the graphite give different damage processes: the void growth at graphite matrix interface for well developped graphite and internal cracking for degenerated graphite. These different damage modes induce different mechanical behaviors. This is confirmed by the comparison between cast iron $A$ and $B$.

For cast iron $\mathrm{A}$, the results presented clearly show that graphite nodules in cast iron serve essentially as void nucleation sites and that as soon as debonding occurs the nodules can be replaced by voids. In cast iron B degenerated graphite gives rise to internal cracking, and due to the localization of the plastic deformation, the mechanism induces higher values of the yield strength and ultimate tensile strength.

\section{Acknowledgements :}

The authors are grateful to D.François and N.Bourgeois for their helpful discussions to this study.

\section{References:}

[1] R. K. Nanstad, AFS Transactions, (1975) 245.

[2] Börje Östensson, Scandinavian Journal of Metallurgy 2 (1973) 194.

[3] W.L.Bradley and M.N.Srinivasan, International Materials Reviews 35 (3) (1990) 129.

[4] R.Salzbrenner, Journal of Materials Science 22 (1987) 2135.

[5] M.S.Cayard, W.L.Bradley, Engineering Fracture Mechanics 33 (1989) 121.

[6] Sun Y. Q. , François D. , Revue de Métallurgie, Oct. (1984) 809.

[7] Rousseau D. , François D. , Mém. Sc. Rev. Mét., Mai (1978) 281.

[8] Sun Y. Q. ,Detraux J. M. , Touzot G. , François D. , Mém. Sc. Rev. Mét. , Avril (1983) 183.

[9] Le Douaron A., Lafont R., Poulain D., Cloitre C., 5th International conference on fracture, Canne, France, 29 March-3 April (1981) 255.

[10] Dong M. , Hu G., Prioul C. Francois D., MECAMAT 93, Fontainebeau, France, July 6-8, (1993) to be published.

[11] Weng G.J., Int.J.Eng.Science 22 (1984) 845.

[12] N.Bourgeois, M.Keyvani, D.Baptiste, D.François, MECAMAT 93, Fontainebeau, France, July 6-8, (1993) to be published.

[13] Eshelby J.D., Proc.R.Soc., London 241 (1957) 376.

[14] Mori, T., Tanaka K., Acta Metallurgica. 21 (1973) 571.

[15] Mura T. Martinus Nijhoff Publishers (1987) 67. 